\title{
ANALISIS DESAIN INTERIOR KANTOR CALL CENTER TELKOMSEL DI GEDUNG INFOMEDIA NUSANTARA, BANDUNG DENGAN PENDEKATAN PSIKOLOGI RUANG
}

\author{
Shafira Andriani, Djoko Murdowo, Rangga Firmansyah \\ Program Studi Desain Interior, Telkom University \\ shafirandrn@student.telkomuniversity.ac.id
}

\begin{abstract}
Abstrak: Kantor Call Center Telkomsel merupakan kantor pelayanan call center selama 24 jam yang difasilitasi oleh perusahaan jasa operator telekomunikasi Telkomsel guna mengoptimalkan mutu pelayanan kepada konsumennya. Pengoptimalan pelayanan ini tentunya dipengaruhi oleh internal perusahaan baik dari segi sistem kerja maupun tempat kerja yang menaungi pekerjaan tersebut. Salah satu studi kasus yang diambil, yaitu Kantor Call Center Telkomsel di Gedung Infomedia Nusantara - Bandung. Desain interior pada kantor ini belum teroptimalisasikan penerapannya dimana memengaruhi kepuasan pekerja tersebut, terutama agen call center. Hal ini sering kali menimbulkan rasa jenuh pada agen yang melakukan pekerjaannya secara berulang melayani konsumen yang tidak jarang memberikan keluhan maupun kritik. Dengan menggunakan metode kualitatif deskriptif (analisis perbandingan kondisi desain interior eksisting dengan teori psikologi ruang (lima aspek yang dapat membentuk desain tempat kerja yang baik)), terbukti bahwa Kantor Call Center Telkomsel ini belum optimal dalam menerapkan desain interior yang baik dalam menunjang kepuasan pekerja guna mengoptimalkan kinerjanya.

Kata Kunci: Psikologi Ruang, Kantor Call Center Telkomsel, Gedung Infomedia Nusantara, Desain Interior.
\end{abstract}

Abstract: Telkomsel Call Center Office is the call center service office for 24 hours which is facilitated by the telecommunications operator service companies Telkomsel in order to optimize the quality of service to its customers. Service optimisation is certainly influenced by internal company both in terms of the work system as well as where its taken place. One case study is taken, i.e. Telkomsel Call Center Office in Gedung Infomedia Nusantara - Bandung. Interior design on this Office has not applied optimally where affect the satisfaction of workers, mainly call center agents. This often raises the boredom on the agents whom do their work repeatedly to serve the consumers who don't rarely give them complaints or criticism. Using a research method of qualitative descriptive (comparative analysis of the condition in existing interior design with the theory of psychological space (five aspects which can form a good workplace design)), it is evident that Telkomsel Call Center Office interior design is not applied optimally to support satisfaction of workers in order to optimize its performance.

Keywords: The Psychology of Space, Telkomsel Call Center Office, Gedung Infomedia Nusantara, Interior Design.

\section{Pendahuluan}

\subsection{Latar Belakang}

Kantor Call Center Telkomsel di Gedung Infomedia, Buah Batu - Bandung, Indonesia merupakan kantor agen call center Telkomsel yang bekerja dalam melayani (agen inbound) dan menawarkan produk (agen outbound) kepada konsumennya. Jumlah Agen yang terdapat Kantor Call Center Telkomsel tersebut mencapai 864 orang, dimana 472 orang merupakan agen inbound dan 392 orang merupakan agen outbound. Operasionalisasi call center Telkomsel aktif selama 24 jam yang dilakukan secara bergiliran dan terjadwal. Oleh karena itu, desain interior pada kantor tersebut sangatlah penting guna menunjang seluruh kebutuhan pekerjanya yang menghabiskan sebagian besar waktu kesehariannya di kantor. Namun pada kenyataanya, penerapan desain interior Kantor Call Center Telkomsel ini memiliki kekurangan yang belum menunjang secara optimal kebutuhan pekerja dimana hal ini berkaitan dalam menunjang kepuasan pekerja guna mengoptimalkan 
kinerjanya untuk melayani konsumen. Dengan menjadikan Kantor Call Center Telkomsel sebagai studi kasus, pembahasan dalam penelitian ini hanya difokuskan pada psikologi ruang dimana berkaitan antara ruang dengan penggunanya yang pada akhirnya memiliki tujuan dalam memberi kepuasan ruang secara psikologis kepada pekerja guna mengoptimalkan kinerjanya.

\section{Kajian Literatur}

\subsection{Pengertian Kantor}

Pengertian kantor menurut Long (2004), kantor berasal dari bahasa Belanda "Kantoor" merupakan sebutan untuk tempat yang digunakan untuk perniagaan atau perusahaan yang dijalankan secara rutin. Kantor bisa hanya berupa suatu kamar atau ruangan kecil maupun bangunan bertingkat tinggi. Sedangkan berdasarkan Kamus Besar Indonesia (KBBI), kantor merupakan sebuat balai (Ruang, gedung dan rumah) tempat yang digunakan untuk mengurus suatu pekerjaan (suatu instansi atau perusahaan); tempat bekerja. Berdasarkan pengertian diatas, maka dapat diambil kesimpulan bahwa kantor adalah ruang bagi sebuah perusahaan untuk mengurus suatu pekerjaan dimana ruang tersebut dapat berupa ruangan kecil atau bangunan bertingkat tinggi.

\subsection{Kantor Call Center Telkomsel}

Telkomsel merupakan salah satu perusahaan operator telekomunikasi seluler di Indonesia. Perusahaan ini menggelar lebih dari 100.000 BTS yang menjangkau sekitar $98 \%$ wilayah populasi di Indonesia. Dalam membantu pelayanan kebutuhan pelanggan, Telkomsel didukung akses call center 24 jam, salah satunya Kantor Call Center Telkomsel di Gedung Infomedia Nusantara Bandung, serta 430 pusat layanan yang tersebar di seluruh Indonesia. Berdasarkan hasil survey eksisting perancangan, Kantor Call Center merupakan kantor informasi terpusat yang digunakan sebagai sarana pemberi informasi dan penerima informasi kepada atau dari konsumennya. Kantor ini biasanya merupakan kantor pusat dimana kantor ini hanya ada satu tempat saja tiap kotanya dan cenderung beroperasi selama 24 jam. Hal ini dikarenakan jumlah pekerja call center yang banyak sehingga dipusatkan pada satu tempat. Pelayan yang menerima atau memberikan informasi disebut dengan agen call center. Kantor Call Center biasanya memiliki dua jenis agen ,yaitu outbound agent dan inbound agent. Outbound agent merupakan agen yang memberi/ menawarkan suatu promo atau produk baru ke pelanggan, sedangkan inbound agent merupakan agen yang menerima panggilan telepon dari pelanggan. Selain agen, pekerja lainnya yang ada di kantor call center, yaitu supervisor (SPV), manager, discontrol, dan lain sebagainya. Pada Kantor Call Center Telkomsel di Gedung Infomedia Buah Batu, Bandung, jumlah agen yang terdapat pada kantor tersebut mencapai 864 orang dimana 472 orang merupakan agen inbound dan 392 orang merupakan agen outbound. Sistem kerja pada agen inbound memiliki jadwal kerja yang berbedabeda setiap orangnya tergantung shift kerja yang ditentukan oleh traffic rate (skema/grafik yang menjabarkan kapan high traffic atau low traffic), sedangkan pada agen outbound jadwal kerjanya berdasarkan jam kerja perusahaan ,yaitu jam 08.00-17.00 WIB.

\subsection{Pengertian Psikologi}

Menurut Michael W. Eysenck dalam Perspectives on Psychology (1994:1), kata "psikologi" berarti hal yang berbeda bagi orang yang berbeda. Kata tersebut berasal dari bahasa Yunani Kuno psyche, yang berarti pikiran atau jiwa, dan logos, yang berarti ilmu. Oleh karena itu, setidaknya 
pada satu waktu, psikologi dapat diartikan sebagai ilmu yang mempelajari tentang jiwa. Psikologi akan sangat berkaitan erat dengan psikologi ruang dimana hal ini memengaruhi psikologi pengguna ruang terhadap lingkungannya.

\subsection{Pengertian Psikologi Pengguna Ruang}

Pembentukan psikologi pengguna ruang terjadi karena adanya interaksi manusia dan lingkungan dimana kedua aspek tersebut merupakan satu kesatuan yang saling berkaitan karena lingkungan memberi pengaruh secara psikologis pada manusia. Berikut proses psikologis interaksi manusia dan lingkungannya.

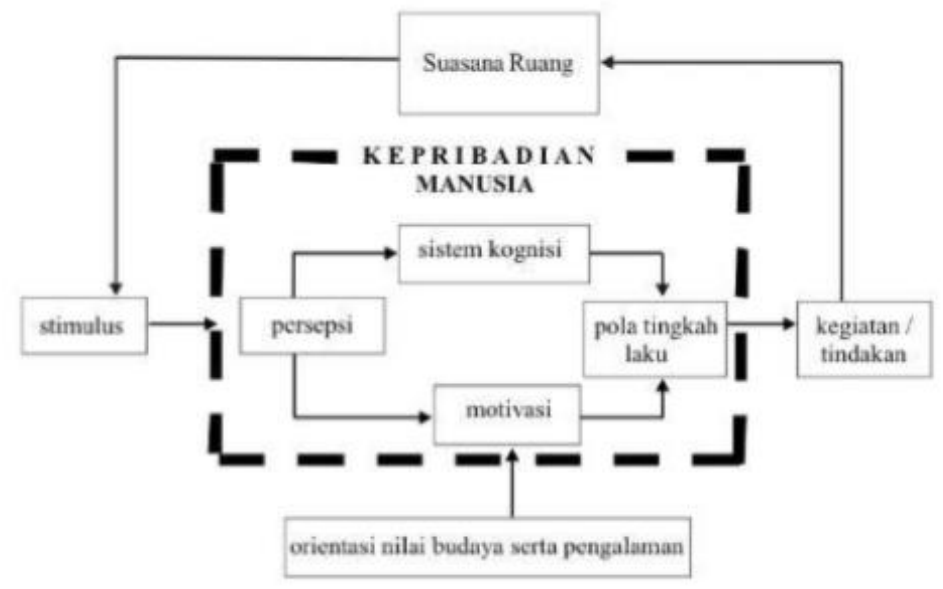

Gambar 2.1. Proses Psikologis Interaksi Manusia dan Lingkungan. Sumber: Jurnal Itenas Rekarupa (2011)

Ruang yang menjadi wadah aktivitas manusia merupakan salah satu lingkungan yang memengaruhi manusia tersebut secara psikologis. Begitu juga dengan kantor. Kantor merupakan ruang yang mewadahi pekerja untuk mencapai target-target perusahaan. Menurut Taufan Hidjaz (2011), perilaku karyawan dan pengunjung di ruang kerja secara langsung maupun tidak langsung berkait dengan unsur-unsur 'sosiologis','psikologis' serta 'psikologi lingkungannya'.

\subsection{Pengertian Psikologi Ruang}

Definisi psikologi ruang menurut Sally Augustin dalam Place Advantage : Applied Psychology for Interior Architecture (2009:30), memproses informasi yang didapatkan dari dunia sekitar kita merupakan sesuatu hal yang penting dimana informasi yang dimaksud merupakan proses dari indera manusia. Ruang menjadi salah satu aspek lingkungan yang sering ditempati oleh manusia dimana ruang memengaruhi manusia tersebut baik secara emosional maupun tingkat rasional. Hal tersebut memengaruhi manusia dari skala tindakan satu ke tindakan lainnya dimana tindakan tersebut terjadi karena efek psikologis dari ruang yang ditempatinya. Penerapan psikologi dalam interior kantor menurut Sally Augustin dalam Place Advantage : Applied Psychology for Interior Architecture (2009:191), ruang kerja merupakan tempat dimana pekerjaan harus diselesaikan (dan diharapkan selesai dengan baik). Bentuk fisik pada ruang kerja dapat membuat kemungkinan lebih 
atau kurang dari apa yang akan terjadi. Ketika seseorang puas dengan tempat kerjanya, mereka akan cenderung lebih puas dengan hasil pekerjaannya (Veitch et al.2007), dan ketika seseorang lebih puas dengan pekerjaannya, mereka akan tetap melakukannya dengan baik secara terusmenerus. Cara orang-orang memandang kesuksesan secara profesional mereka memengaruhi persepsi mereka sendiri pada desain tempat kerjanya (Fischer, Tarquinio, dan Vischer ,2004). Orang-orang yang merasa bahwa mereka merupakan orang sukses secara profesional umumnya lebih puas dengan lingkungan kerja fisik mereka daripada orang-orang yang tidak merasa bahwa mereka sukses secara profesional. Orang-orang yang merasa sukses akan lebih puas dengan aspek fisik kerja mereka, seperti ukuran, kesan estetika dan privasi yang dirasakan. Orang-orang yang merasa bahwa mereka lebih sukses juga lebih cenderung melihat tempat kerja mereka sebagai sesuatu yang menyehatkan. Orang-orang yang tidak puas dengan pekerjaannya cenderung lebih banyak mengeluh tentang lingkungan kerja yang ia tekuni. Pengaruh perasaan pekerja tentang kesuksesan di tempat kerja memberi jawaban sederhana bahwa tidak semua variasi desain tempat kerja dapat memberi solusi atas emosionalitas serta motivasi pekerja tersebut. Berikut aspek-aspek yang dapat membentuk desain tempat kerja yang baik menurut Sally Augustin dalam Place Advantage : Applied Psychology for Interior Architecture (2009:193-218).

A. Communicating (komunikasi) Implikasi desain: menerapkan desain yang akuratif dan komunikatif pada ruang kerja. Contoh: penerapan organisasi ruang yang jelas, efektif, dan efisien, penerapan kesan homy pada kantor dimana pekerja dapat melakukan self-organizing, penerapan signage yang jelas dan umum pada interior, penerapan cooperate identity pada kantor dimana konsisten dengan budaya perusahaan itu sendiri.

B. Comforting (kenyamanan) Implikasi desain: menerapkan aspek lingkungan fisik pada ruang kerja atau hal lain yang dapat menciptakan suasana hati pekerja guna meningkatkan kinerjanya. Contoh: penggunaan warna brand perusahaan dengan memainkan brightness dan saturation, penerapan area shout-out, memfasilitasi sarana kreatif, dan self-control di workspace.

C. Complying (kesesuaian) Implikasi desain: menciptakan kesesuaian antara pekerja dengan tempat kerjanya. Contoh: menggabungkan pemandangan alam dan elemen hijau pada ruang kerja, cahaya matahari (tetapi bukan yang menyilaukan) pada tempat kerja harus dioptimalkan, warna-warna yang digunakan di permukaan dan pencahayaan harus dipilih dengan hati-hati, tempat- tempat yang diperlukan konsentrasi penuh harus diberi kedap suara, memberi perbedaan desain status berdasarkan jabatan pekerjaan, penerapan partisi guna menciptakan private space pada ruang-ruang tertentu, fasilitas loker guna menciptakan suasana rapi dan bersih pada workspace, penerapan walkways pattern pada lantai guna meningkatkan kecenderungan berjalan di dalam kantor, membagi territorial baik untuk divisi kelompok maupun individu, membuat ruang kolaborasi guna interaksi informal antar pekerja, tempat pekerja harus terdesain dengan baik, meletakan small cellular office pada ruangan yang tertutup dengan partisi kaca, dan lain sebagainya.

D. Challenging (tantangan) Implikasi desain: menciptakan kesan menantang pada ruang untuk memotivasi pekerja. Contoh: memberi area kreatif untuk pekerja, mengorganisir tempat duduk agar dapat melihat satu sama lain.

E. Continuing (lanjutan) Membuat ruang kantor yang memfasilitasi pekerja untuk melakukan multitasking. Contohnya: penerapan open-plan office. 


\section{Metode Penelitian}

Penelitian ini menggunakan studi kasus Kantor Call Center Telkomsel dengan acuan teori psikologi ruang (lima aspek yang dapat membentuk desain tempat kerja yang baik). Penelitian ini menggunakan metode kualitatif deskritif yang akan menghasilkan analisis perbandingan kondisi desain interior eksisting dengan teori psikologi ruang (lima aspek yang dapat membentuk desain tempat kerja yang baik). Berikut merupakan tahapan penelitian yang dilakukan:

\subsection{Metode Pengumpulan Data}

Metode pengumpulan data merupakan tahap dimana terdapat dua jenis data yang dikumpulkan ,yaitu data primer dan data sekunder. Data primer merupakan data hasil survey Kantor Call Center Telkomsel yang terletak di lantai 5 (Inbound Call Center) dan lantai 6 (Outbound Call Center) pada Gedung Infomedia Nusantara. Data primer tersebut dikumpulkan melalui observasi, dokumentasi, pengukuran, wawancara. Sedangkan, data sekunder merupakan data yang berasal dari literatur dimana data ini dapat berupa jurnal, buku terkait perancangan, dan lain sebagainya. Selain literatur tertulis dalam bentuk fisik, literatur juga dapat ditemukan melalui media internet salah satunya ebook. Data literatur yang digunakan sebagai acuan utama pendekatan psikologi ini bersumber dari buku Place Advantage : Applied Psychology for Interior Architecture (2009) oleh Sally Augustin. Buku ini menjelaskan tentang perancangan desain interior yang baik dengan memerhatikan beberapa aspek yang berkaitan dengan psikologi ruang.

\subsection{Metode Analisa Data}

Pada metode ini, data hasil survey studi kasus Kantor Call Center Telkomsel yang sudah terkumpul diuraikan dan dianalisa berdasarkan elemen desain interior (plafon, dinding, dan lantai) dan elemen pengisi ruang (furniture) dimana pada akhirnya akan dilakukan perbandingan dengan lima aspek desain interior terkait psikologi ruang acuan literatur Place Advantage : Applied Psychology for Interior Architecture dan dikelompokan berdasarkan kekurangan dan kelebihan yang ada pada kondisi eksisting. Proses analisa akan dilakukan secara kualitatif deskriptif untuk mendapat gambaran secara jelas kekurangan dan kelebihan apa saja yang ditemukan terkait desain interior Kantor Call Center Telkomsel. Setelah metoda analisa data ini selesai, hasil penelitian akan digarisbesarkan pada kesimpulan.

\section{Pembahasan dan Hasil/Temuan \\ 4.1 Kondisi Kantor Call Center Telkomsel}

Kantor Call Center Telkomsel ini berlokasikan di Gedung Infomedia Nusantara di Jl. Terusan Buah Batu No.33, Batununggal, Bandung Kidul, Kota Bandung, Jawa Barat 40266. Gedung ini merupakan milik perusahaan PT. Telkom Indonesia. Iklim yang ada pada daerah gedung ini merupakan iklim daerah Bandung dimana cenderung tropis dengan suhu rendah. Pada area Gedung Infomedia Nusantara ini merupakan kawasan industri dimana tingkat kebisingan dan polusi udara cenderung tinggi. Kantor Call Center Telkomsel ini berlokasikan di lantai 5 dan 6 yang masing masing lantainya memiliki luasan $2.847 \mathrm{~m} 2$, dengan demikian total luasan kedua lantai mencapai $5.694 \mathrm{~m} 2$. 

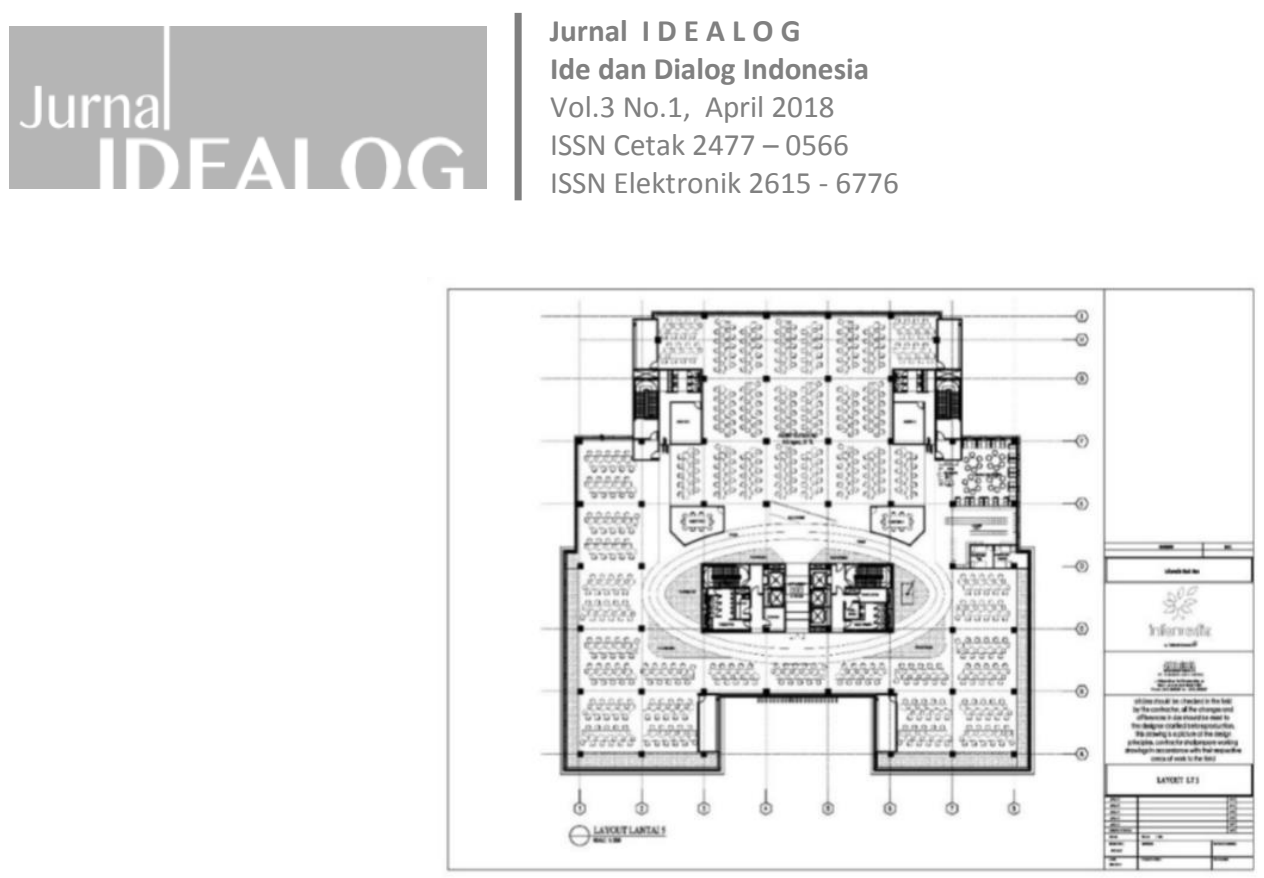

Gambar 3.2. Layout Lantai 5 Kantor Call Center Telkomsel Sumber:

Dokumen Perusahaan (2018)

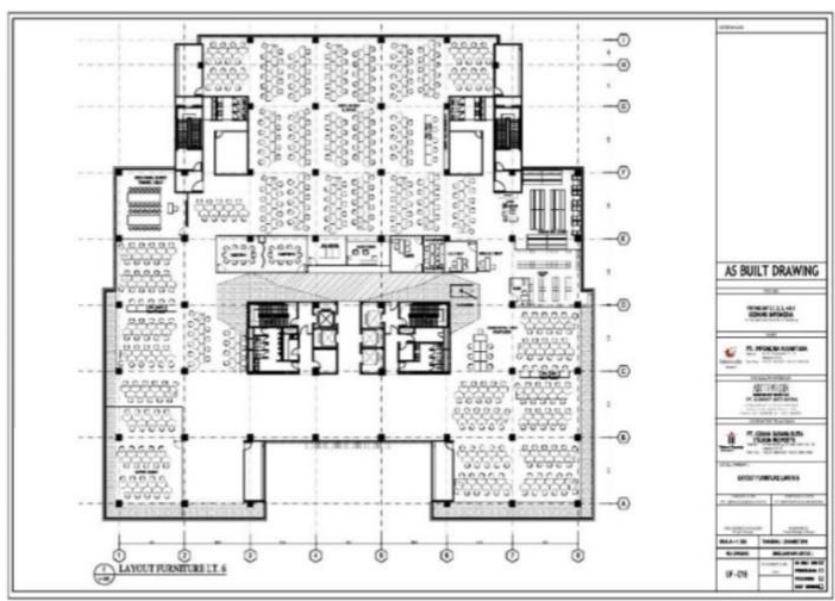

Gambar 3.3. Layout Lantai 6 Kantor Call Center Telkomsel Sumber: Dokumen Perusahaan (2018)

\subsection{Analisa Elemen Desain Interior dan Elemen Pengisi Ruang}

Analisa dilakukan berdasarkan ruang-ruang yang ada di Kantor Call Center Telkomsel dimana elemen ruang tersebut dibandingkan dengan lima aspek yang dapat membentuk desain tempat kerja yang baik berdasarkan acuan literatur Place Advantage : Applied Psychology for Interior Architecture. Kelima aspek tersebut, yaitu Communicating, Comforting, Complying, Challenging, dan Continuing yang sudah dijabarkan dalam kajian literatur psikologi ruang.

\subsubsection{Resepsionis dan Hall}




\section{Berikut adalah kondisi Ruang Resepsionis dan Hall}
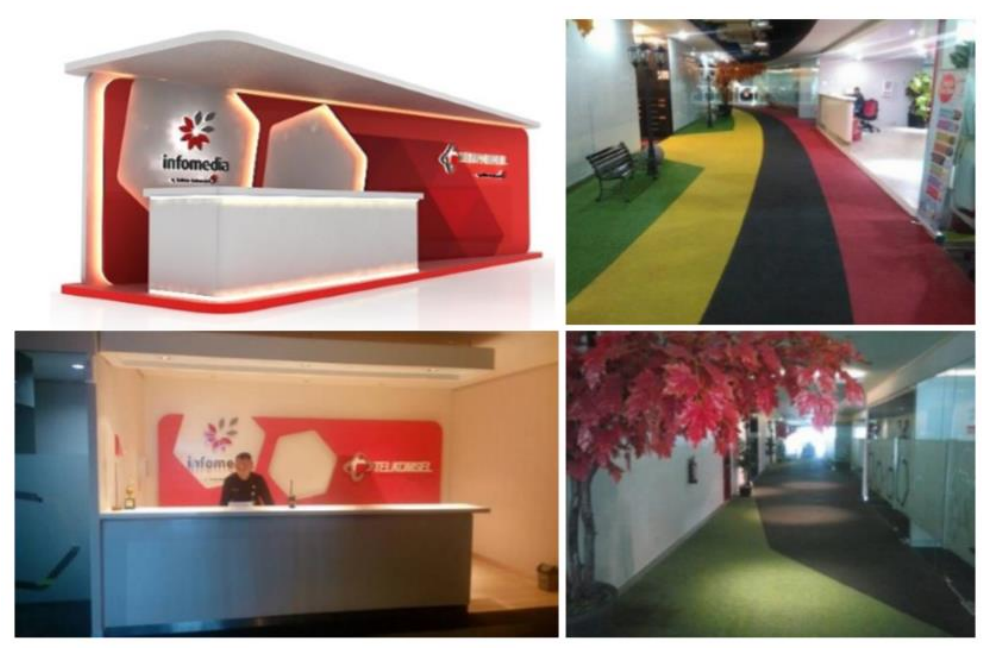

Gambar 3.4. Resepsionis dan Hall Lantai 5 (atas) Lantai 6 (bawah) Sumber: Dokumen Perusahaan (2018)

Tabel 3.1. Tabel Analisa Resepsionis dan Hall Sumber: Dokumen Pribadi (2018)

\begin{tabular}{|c|c|c|}
\hline Aspek & Analisa (+) & Analisa (-) \\
\hline Communicating & $\begin{array}{l}\text { Organisasi ruang terkait peletakan area } \\
\text { sudah baik (dekat dengan entrance), } \\
\text { penerapan cooperate identity pada } \\
\text { resepsionis lantai } 5 \text { terlihat dari bentuk dan } \\
\text { warna yang diterapkan secara keseluruhan. }\end{array}$ & $\begin{array}{l}\text { Resepsionis lantai } 6 \text { belum diterapkan secara } \\
\text { optimal dan cenderung menciptakan kesan } \\
\text { flat, penerapan tanda jalur lokasi ruang dan } \\
\text { nama ruang tidak ditemukan, jalur evakuasi } \\
\text { pada keadaan darurat kurang informatif } \\
\text { karena hanya di jelaskan lewat layout. }\end{array}$ \\
\hline \multirow[t]{2}{*}{ Comforting } & - & $\begin{array}{l}\text { Penggunaan warna pada hall area lantai } 5 \\
\text { cenderung tidak konsisten dengan warna }\end{array}$ \\
\hline & & $\begin{array}{l}\text { cooperate identity (merah, putih, abu-abu) } \\
\text { dan penerapannya kurang variatif dimana } \\
\text { tidak memainkan skema warna, sedangkan } \\
\text { hall area lantai } 6 \text { tidak menciptakan warna } \\
\text { cooperate identity. }\end{array}$ \\
\hline Complying & $\begin{array}{l}\text { Penerapan warna cahaya sudah baik, } \\
\text { Penerapan walkways pattern pada hall } \\
\text { area lantai } 5 \text { sudah diterapkan. }\end{array}$ & $\begin{array}{l}\text { Kurangnya penerapan tanaman, penerapan } \\
\text { walkways pattern pada hall area lantai } 6 \\
\text { belum diterapkan, penerapan display tentang } \\
\text { perusahaan belum diterapkan. }\end{array}$ \\
\hline Challenging & $\begin{array}{l}\text { Terdapat wall of stars (area papan } \\
\text { penghargaan) pada eksisting dimana } \\
\text { berguna sebagai sarana motivasi pekerja. }\end{array}$ & ( \\
\hline Continuing & $\begin{array}{l}\text { Penerapan open-plan office pada eksisting. } \\
\text { Hal ini berguna dalam mempermudah } \\
\text { komunikasi dan membantu terbentuknya } \\
\text { jaringan antar pekerja. }\end{array}$ & - \\
\hline
\end{tabular}

Analisa yang dilakukan menunjukkan Aspek Challenging dan Continuing berperan pada ruang Resepsionis dan Hall ini. 


\subsubsection{Meeting Room}

Berikut adalah kondisi Ruang Rapat

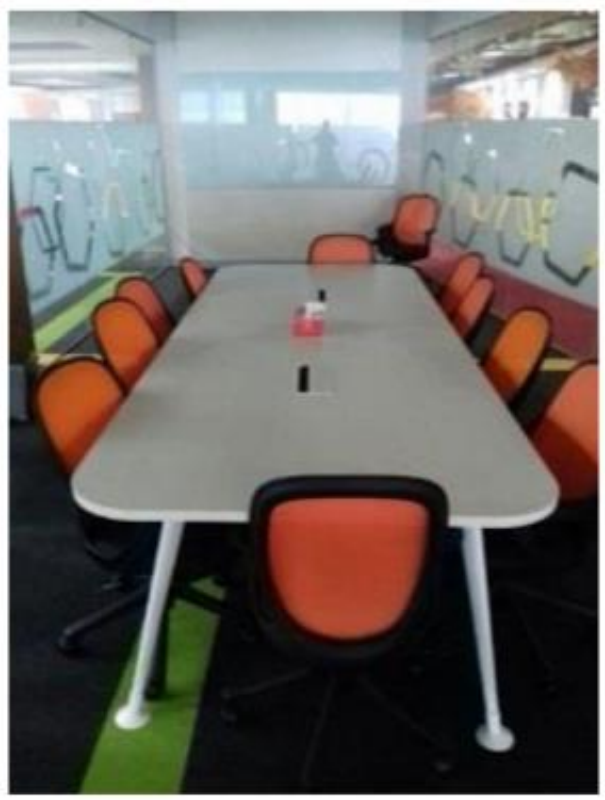

Gambar 3.5. Meeting Room Sumber: Dokumen Perusahaan (2018)

Tabel 3.2. Tabel Analisa Meeting Room Sumber: Dokumen Pribadi (2018)

\begin{tabular}{|c|l|l|}
\hline Aspek & \multicolumn{1}{|c|}{ Analisa (+) } & \multicolumn{1}{c|}{ Analisa (-) } \\
\hline \hline Communicating & $\begin{array}{l}\text { Organisasi ruang terkait peletakan area } \\
\text { sudah baik (center). }\end{array}$ & $\begin{array}{l}\text { Penerapan furniture tidak multifungsi, tidak } \\
\text { ada nama ruang, penerapan cooperate } \\
\text { identity belum optimal. }\end{array}$ \\
\hline Comforting & \multicolumn{1}{|c|}{$\begin{array}{l}\text { Penggunaan warna cenderung tidak } \\
\text { konsisten dengan warna cooperate identity } \\
\text { (merah, putih, abu-abu) dan penerapannya } \\
\text { kurang variatif dimana tidak memainkan } \\
\text { skema warna. }\end{array}$} \\
\hline Complying & $\begin{array}{l}\text { Penerapan warna cahaya sudah baik, } \\
\text { adanya partisi kaca yang memisahkan } \\
\text { ruang dalam dan luar, penerapan sound- } \\
\text { proofed terdapat pada partisi. }\end{array}$ & $\begin{array}{l}\text { Kurangnya penerapan tanaman, penerapan } \\
\text { transparent window coating tidak diterapkan } \\
\text { untuk mengurangi silau, tidak ada variasi } \\
\text { bentuk meja meeting, tidak ada computer } \\
\text { display, tidak ada sarana komunikasi antar } \\
\text { ruang dalam dan luar. }\end{array}$ \\
\hline Challenging & $\begin{array}{l}\text { Layout tempat duduk sudah terorganisir } \\
\text { sesuai standar meeting room (saling } \\
\text { berhadapan) }\end{array}$ & $\begin{array}{l}\text { Penerapan open-plan office yang tetap } \\
\text { memerhatikan privacy ruang pada meeting } \\
\text { room ini. }\end{array}$ \\
\hline Continuing
\end{tabular}

Analisa yang dilakukan menunjukkan Aspek Challenging dan Continuing berperan pada ruang Rapat ini. 


\subsubsection{Supervisor Area, Counseling Room, Couching Room, Manager dan Adm. Manager Room, LO Room}

Berikut adalah kondisi Ruang Supervisor, Counseling, Couching, Manager dan Adm. Manager, LO.
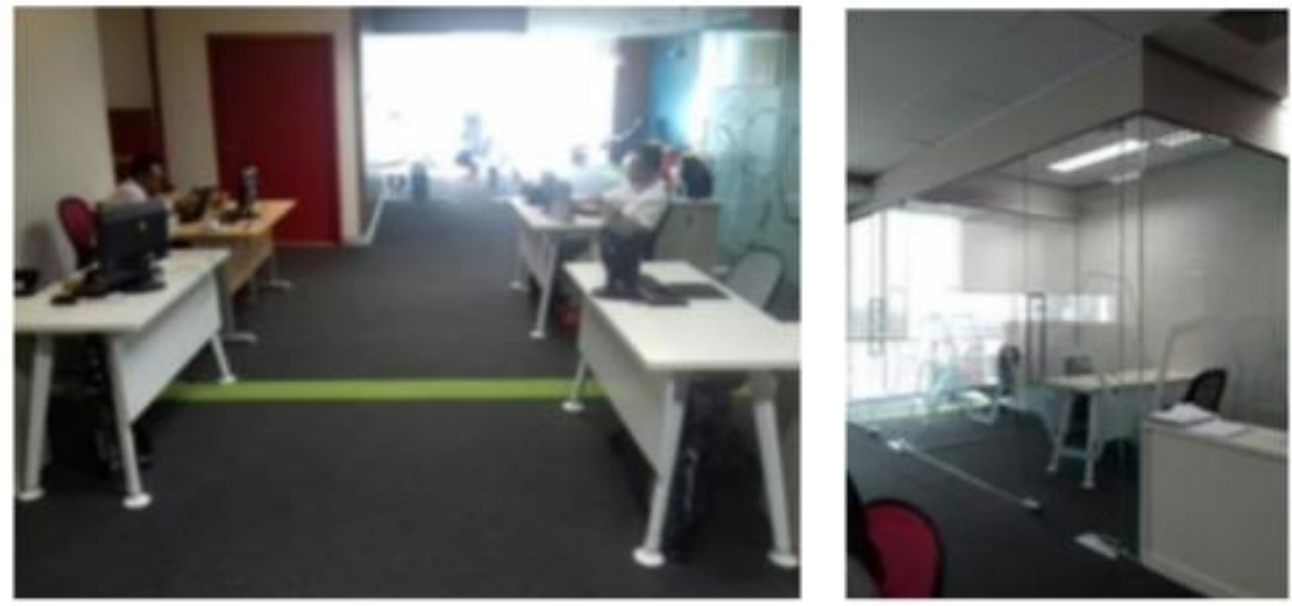

Gambar 3.6. SPV Area (kiri) Counseling Room, dan Couching Room (kanan) Sumber: Dokumen Perusahaan (2018)

Tabel 3.3. Tabel Analisa Supervisor Area, Counseling Room, Couching Room, Manager dan Adm.

\begin{tabular}{|c|c|c|}
\hline Aspek & Analisa (+) & Analisa ( () \\
\hline Communicating & $\begin{array}{l}\text { Organisasi ruang counching room dan } \\
\text { counseling room bersebelahan, SPV } \\
\text { berada dekat dengan staff. }\end{array}$ & $\begin{array}{l}\text { Penerapan furniture tidak multifungsi, tidak } \\
\text { ada nama ruang, penerapan cooperate } \\
\text { identity belum optimal, penempatan } \\
\text { adm.manager harusnya terpisah dengan } \\
\text { ruang manager, ruangan belum terorganisir } \\
\text { (ruang manager, admmanager,LO harusnya } \\
\text { bersebelahan dan berada dekat jendela), } \\
\text { tidak ada sarana self-organizing pada ruang } \\
\text { kerja pribadi (manager, LO, admmanager). }\end{array}$ \\
\hline Comforting & - & $\begin{array}{l}\text { Penggunaan warna cenderung tidak } \\
\text { konsisten dengan warna cooperate identity } \\
\text { (merah, putih, abu-abu) dan penerapannya } \\
\text { kurang variatif dimana tidak memainkan } \\
\text { skema warna, tidak ada sarana self-control } \\
\text { pada ruang kerja pribadi (task lighting } \\
\text { dengan dimmer), tidak ada ciri khas aroma } \\
\text { yang dapat membangkitkan mood pekerja. }\end{array}$ \\
\hline Complying & $\begin{array}{l}\text { Penerapan warna cahaya sudah baik, } \\
\text { adanya partisi kaca yang memisahkan } \\
\text { ruang dalam dan luar, penerapan sound- } \\
\text { proofed terdapat pada partisi. }\end{array}$ & $\begin{array}{l}\text { Kurangnya penerapan tanaman, penerapan } \\
\text { transparent window coating tidak diterapkan } \\
\text { untuk mengurangi silau, elemen desain } \\
\text { interior terlalu monoton sehingga pekerja } \\
\text { cenderung sulit berkonsentrasi dan mencari } \\
\text { energi di ruang lain, tidak ada hirarki desain }\end{array}$ \\
\hline Challenging & $\begin{array}{l}\text { Layout tempat duduk sudah terorganisir } \\
\text { sesuai standar. }\end{array}$ & $\begin{array}{l}\text { Tidak ada sarana kreatif pada ruang kerja } \\
\text { pribadi (contoh: fasilitas corkboard } \\
\text { whiteboard sebagai tempat penjabaran } \\
\text { target) }\end{array}$ \\
\hline Continuing & $\begin{array}{l}\text { Penerapan open-plan office yang tetap } \\
\text { memerhatikan privacy ruang kerja pribadi } \\
\text { (manager,LO,adm manager). }\end{array}$ & - \\
\hline
\end{tabular}


Analisa yang dilakukan menunjukkan Aspek Continuing berperan pada ruang Ruang Supervisor, Counseling, Couching, Manager, Adm. Manager, dan LO.ini.

\subsubsection{Canteen (Dining and Lounge)}

\section{Berikut adalah kondisi Ruang Kantin}
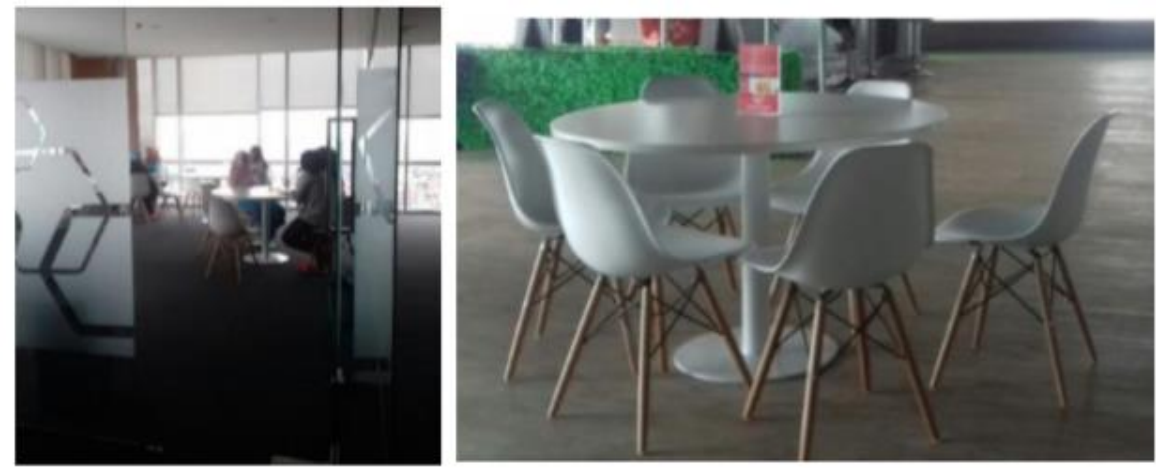

Gambar 3.7. Canteen (Dining and Lounge) Sumber: Dokumen Perusahaan (2018)

Tabel 3.4. Tabel Analisa Canteen (Dining and Lounge) Sumber: Dokumen Pribadi (2018)

\begin{tabular}{|c|c|c|}
\hline Aspek & Analisa (+) & Analisa (-) \\
\hline Communicating & $\begin{array}{l}\text { Organisasi ruang terkait peletakan ruang } \\
\text { sudah baik (berada di dekat jendela; } \\
\text { sebagai sarana view pengguna ruang). }\end{array}$ & $\begin{array}{l}\text { Penerapan furniture tidak variatif, tidak ada } \\
\text { nama ruang, penerapan cooperate identity } \\
\text { belum optimal. }\end{array}$ \\
\hline Comforting & (n) & $\begin{array}{l}\text { Penggunaan warna cenderung tidak } \\
\text { konsisten dengan warna cooperate identity } \\
\text { (merah, putih, abu-abu) dan penerapannya } \\
\text { kurang variatif dimana tidak memainkan } \\
\text { skema warna. }\end{array}$ \\
\hline Complying & Penerapan warna cahaya sudah baik. & $\begin{array}{l}\text { Kurangnya penerapan tanaman, penerapan } \\
\text { transparent window coating tidak diterapkan } \\
\text { untuk mengurangi silau, elemen desain } \\
\text { interior terlalu monoton sehingga pekerja } \\
\text { cenderung bosan, ruang tidak efisien karena } \\
\text { tidak bisa menampung banyak orang, ruang } \\
\text { tidak menciptakan kolaborasi. }\end{array}$ \\
\hline Challenging & $\begin{array}{l}\text { Layout tempat duduk sudah terorganisir } \\
\text { sesuai standar. }\end{array}$ & 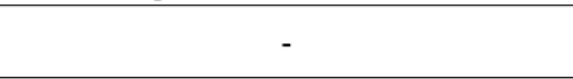 \\
\hline Contimuing & ${ }^{2}$ & $\begin{array}{l}\text { Penerapan partisi kaca tidak mencerminkan } \\
\text { open-plan office. Hal ini berlaku pada } \\
\text { ruang/area yang memfasilitasi kegiatan } \\
\text { informal seperti kantin. }\end{array}$ \\
\hline
\end{tabular}

Analisa yang dilakukan menunjukkan Aspek Challenging berperan pada Ruang Kantin ini. 
4.2.5 Inbound \& Outbound Agent Area, Support Room, dan Training Room Berikut adalah kondisi Ruang Inbound \& Outbound Agent, Support, dan Training.
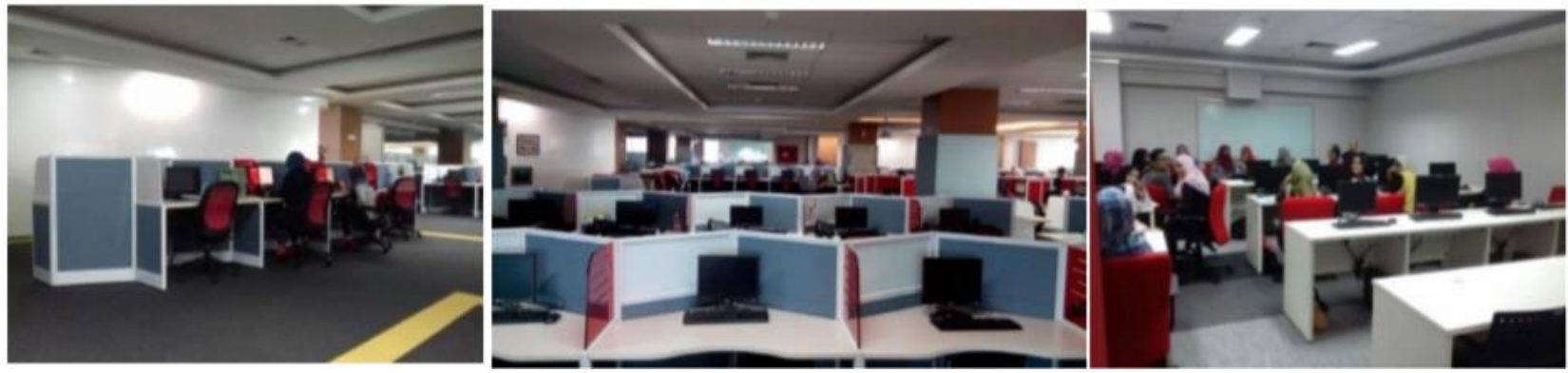

Gambar 3.8. Inbound \& Outbound Agent Area (kiri dan tengah), Training Room (kanan) Sumber: Dokumen Perusahaan (2018)

Tabel 3.5. Tabel Analisa Inbound \& Outbound Agent Area, Support Room, dan Training Room Sumber: Dokumen Pribadi (2018)

\begin{tabular}{|c|c|c|}
\hline Aspek & Analisa (+) & Analisa (-) \\
\hline Communicating & $\begin{array}{l}\text { Organisasi ruang terkait peletakan agent } \\
\text { area dan training room sudah baik (berada } \\
\text { tersebar diseluruh area kantor (area agen) } \\
\text { dan dekat dengan jendela (beberapa area)) } \\
\text { sedangkan, peletakan support room }\end{array}$ & $\begin{array}{l}\text { Penerapan furniture tidak multifungsi, tidak } \\
\text { ada nama ruang, penerapan cooperate } \\
\text { identity belum optimal. }\end{array}$ \\
\hline & $\begin{array}{llll}\begin{array}{l}\text { seharusnya terletak dilantai } 5 \\
\text { adanya perubahan lokasi. }\end{array} & \\
\end{array}$ & \\
\hline Comforting & e & $\begin{array}{l}\text { Penggunaan warna cenderung tidak } \\
\text { konsisten dengan warna cooperate identity } \\
\text { (merah, putih, abu-abu) dan penerapannya } \\
\text { kurang variatif dimana tidak memainkan } \\
\text { skema warna, tidak ada sarana self-control } \\
\text { pada ruang kerja pribadi (task lighting } \\
\text { dengan dimmer), tidak ada ciri khas aroma } \\
\text { yang dapat membangkitkan mood pekerja, } \\
\text { tidak ada area bebas beropini (shout-out } \\
\text { area) dan seating plot area di area } \\
\text { workspace agent. }\end{array}$ \\
\hline Complying & $\begin{array}{l}\text { Adanya partisi kaca yang memisahkan } \\
\text { ruang dalam dan luar (support room dan } \\
\text { training room), penerapan sound-proofed } \\
\text { terdapat pada partisi, terdapat visual } \\
\text { shielding pada workspace antar agen, } \\
\text { konsep tempat kerja yang selalu berpindah- } \\
\text { pindah memberi kecenderungan pada agen } \\
\text { agar tidak bosan, peletakan team leader dan } \\
\text { agen yang berdekatan. }\end{array}$ & $\begin{array}{l}\text { Kurangnya penerapan tanaman, penerapan } \\
\text { transparent window coating tidak diterapkan } \\
\text { untuk mengurangi silau, elemen desain } \\
\text { interior terlalu monoton sehingga pekerja } \\
\text { cenderung sulit berkonsentrasi dan mencari } \\
\text { energi di ruang lain, jenis warna yang } \\
\text { digunakan seharusnya under-warmer color } \\
(3000 \mathrm{~K}) \text {, penerapan walkways pattern di } \\
\text { area sirkulasi tidak ada, tidak ada } \\
\text { multifunction storage pada workspace. }\end{array}$ \\
\hline Challenging & $\begin{array}{l}\text { Layout tempat duduk sudah terorganisir } \\
\text { sesuai standar, adanya sarana kreatif pada } \\
\text { masing-masing workspace (agen dan } \\
\text { support) (contoh: fasilitas whiteboard } \\
\text { sebagai sarana menulis) }\end{array}$ & 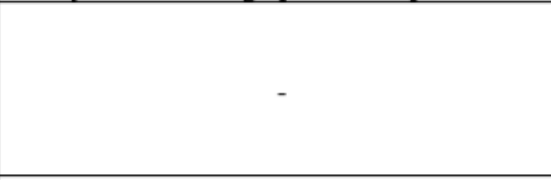 \\
\hline Continuing & $\begin{array}{l}\text { Penerapan open-plan office yang tetap } \\
\text { memerhatikan privacy pada ruang kerja } \\
\text { grup seperti support room dan training } \\
\text { room. }\end{array}$ & - \\
\hline
\end{tabular}


Analisa yang dilakukan menunjukkan Aspek Challenging dan Continuing yang berperan pada Ruang Inbound \& Outbound Agent, Support, dan Training ini.

\subsubsection{Locker Area}

Berikut adalah kondisi Ruang Loker

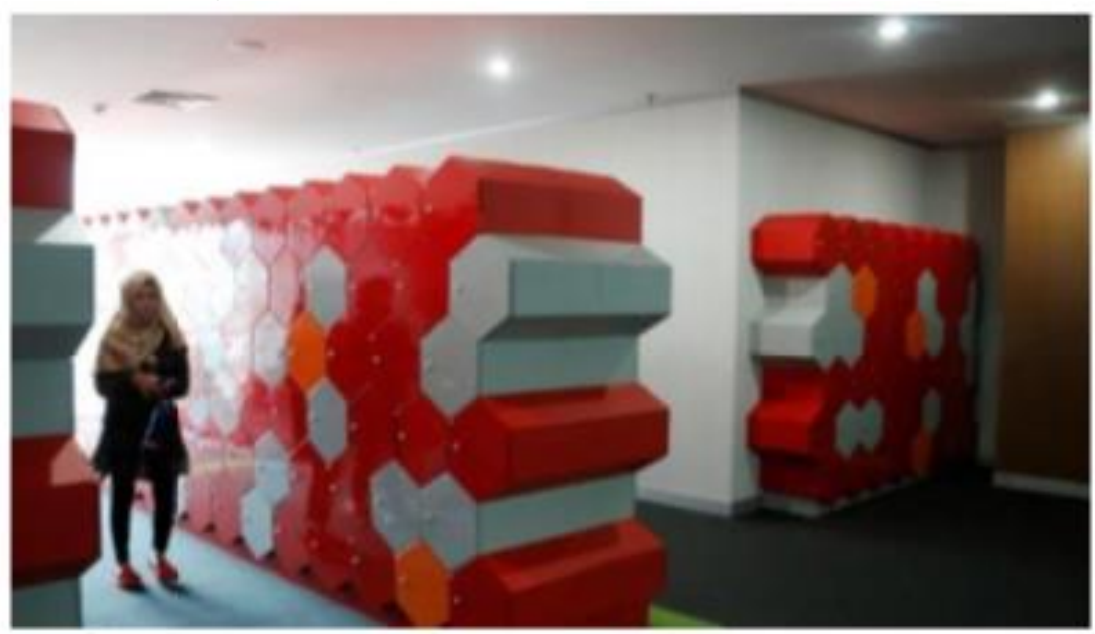

Gambar 3.9. Locker Area Sumber: Dokumen Perusahaan (2018)

Tabel 3.6. Tabel Analisa Locker Area

Sumber: Dokumen Pribadi (2018)

\begin{tabular}{|c|l|l|}
\hline Aspek & \multicolumn{1}{|c|}{ Analisa ( + ) } & \multicolumn{1}{|c|}{ Analisa (-) } \\
\hline \hline Communicating & $\begin{array}{l}\text { Penerapan cooperate identity pada elemen } \\
\text { pengisi ruang sudah baik. }\end{array}$ & $\begin{array}{l}\text { Organisasi ruang terkait peletakan area } \\
\text { seharusnya dekat dengan area masuk, tidak } \\
\text { ada nama ruang. }\end{array}$ \\
\hline Comforting & $\begin{array}{l}\text { Penggunaan warna cenderung konsisten } \\
\text { dengan warna cooperate identity (merah, } \\
\text { putih, abu-abu). }\end{array}$ & $\begin{array}{l}\text { Penerapan warna tidak menggunakan skema } \\
\text { warna (memainkan brightness dan } \\
\text { saturation). }\end{array}$ \\
\hline \hline Challenging & $\begin{array}{l}\text { Adanya sarana storage (loker) dapat } \\
\text { menciptakan mood yang baik terkait } \\
\text { kerapihan pada pekerja. }\end{array}$ & $\begin{array}{l}\text { Penerapan transparent window coating tidak } \\
\text { diterapkan untuk mengurangi silau, elemen } \\
\text { pembentuk ruang terlalu monoton, ruang } \\
\text { tidak efektif karena bentuk loker yang } \\
\text { menyisakan ruang. }\end{array}$ \\
\hline Continuing & $\begin{array}{l}\text { Layout loker sudah teroganisir dengan } \\
\text { sirkulasi yang baik. }\end{array}$ & $\begin{array}{l}\text { Penerapan konsep open-plan office terlihat } \\
\text { pada area loker yang tidak menggunakan } \\
\text { partisi. }\end{array}$ \\
\hline
\end{tabular}

Analisa yang dilakukan menunjukkan Aspek Challenging dan Continuing yang berperan pada Ruang Locker ini. 


\subsubsection{Entertaining Area}

\section{Berikut adalah kondisi Ruang Entertaining}

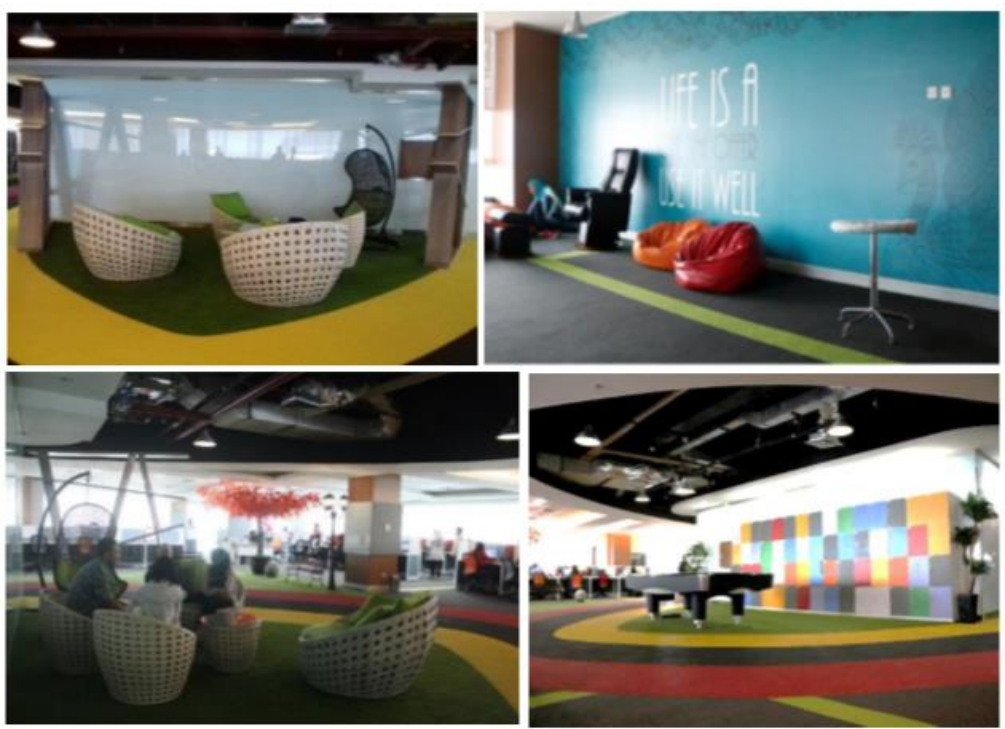

Gambar 3.10. Entertaining Area Sumber: Dokumen Perusahaan (2018)

Tabel 3.7. Tabel Analisa Entertaining Area

Sumber: Dokumen Pribadi (2018)

\begin{tabular}{|c|c|c|}
\hline Aspek & Analisa ( + ) & Analisa (-) \\
\hline Communicating & 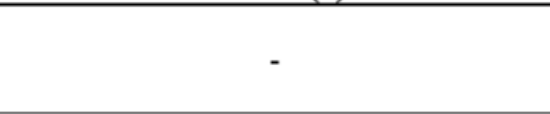 & $\begin{array}{l}\text { Penerapan cooperate identity belum optimal, } \\
\text { organisasi ruang terkait peletakan area belum } \\
\text { tersebar keseluruh workspace area. }\end{array}$ \\
\hline Comforting & - & $\begin{array}{l}\text { Penggunaan warna cenderung tidak } \\
\text { konsisten dengan warna cooperate identity } \\
\text { (merah, putih, abu-abu) dan penerapannya } \\
\text { kurang variatif dimana tidak memainkan } \\
\text { skema warna. }\end{array}$ \\
\hline Complying & $\begin{array}{l}\text { Adanya entertaining area dan lounge area } \\
\text { yang bertujuan untuk menjadi sarana } \\
\text { refreshing para pekerja. }\end{array}$ & $\begin{array}{l}\text { Penerapan transparent window coating tidak } \\
\text { diterapkan untuk mengurangi silau, elemen } \\
\text { pembentuk ruang terlalu monoton, area tidak } \\
\text { memunculkan ciri khas sebagai } \\
\text { "entertaining area" itu sendiri, area kurang } \\
\text { menciptakan suasana kolaboratif, pengisi } \\
\text { ruang tidak bervariasi. }\end{array}$ \\
\hline Challenging & $\begin{array}{l}\text { Layout pengisi ruang sudah teroganisir } \\
\text { dengan sirkulasi yang baik. }\end{array}$ & ( \\
\hline Contimuing & $\begin{array}{l}\text { Penerapan konsep open-plan office } \\
\text { diterapkan pada entertaining area ini guna } \\
\text { menciptakan keterbukaan dan komunikasi } \\
\text { antar pekerja. }\end{array}$ & - \\
\hline
\end{tabular}

Analisa yang dilakukan menunjukkan Aspek Challenging dan Continuing yang berperan pada Ruang Entertaining ini. 


\section{Kesimpulan}

Penelitian ini menggunakan metode kualitatif deskriptif dengan menganalisa elemen desain interior secara spasial dan visual dimana hal ini membantu proses pengelompokan baik kekurangan maupun kelebihan desain interior yang ada pada studi kasus terkait. Proses perbandingan dilakukan antara elemen desain interior studi kasus: Kantor Call Center Telkomsel dengan teori aspek-aspek desain interior kantor yang baik berdasarkan literatur Place Advantage: Applied Psychology for Interior Architecture dimana berkaitan dengan psikologi ruang. Acuan literatur tersebut dapat digarisbesarkan bahwa dalam mendesain interior suatu kantor ada beberapa aspek yang harus diperhatikan, yaitu Communicating, Comforting, Complying, Challenging, dan Continuing. Seluruh aspek tersebut perlu diperhatikan karena dapat memengaruhi kepuasan pekerja itu sendiri. Aspek tersebut berkaitan dari desain workspace sampai dengan seluruh ruang dan area yang ada pada kantor terkait. Efek psikologi yang dipengaruhi oleh ruang pada penggunanya, dimana pada kantor ialah pekerja, merupakan suatu hal yang penting karena berkaitan pula dengan kepuasan pekerja tersebut dalam mengoptimalkan kinerjanya.

Setelah dilakukan pengumpulan data dan analisa, dapat digaris-besarkan bahwa Kantor Call Center Telkomsel ini memiliki banyak kekurangan dalam menunjang kepuasan pekerja guna mengoptimalkan kinerjanya. Aspek yang paling menonjol berdasarkan kriteria Place Advantage adalah aspek Challenging, dan Continuing yang lebih menekankan area kreatif untuk pekerja, dan organisasi ruang yag baik, serta penerapan open plan yang mendukung kreatifitas dan memfasilitasi pekerja untuk melakukan multitasking.

Meskipun kondisi kantor eksisting saat ini cukup terfasilitasi agar kegiatan kerja berjalan lancar, hal terkait desain interior yang memerhatikan psikologi ruang ini tanpa disadari memengaruhi performa atau kinerja pekerja dimana memberikan efek negatif pula untuk perusahaan. Efek negatif yang muncul dalam jangka waktu dekat atau lambat dapat menimbulkan beberapa masalah. Contoh: adanya pengunduran diri dari pekerja karena tidak puas dan tidak betah akan suasana kantor yang membosankan. Dengan demikian, diharapkan penelitian ini dapat memberikan manfaat serta ilmu bagi khalayak umum sehingga patut untuk dijadikan contoh dalam merancang interior kantor dengan memerhatikan aspek-aspek terkait psikologi ruang yang sudah dijabarkan sebelumnya.

\section{Daftar Pustaka}

[1] Eysenck, Michael W. (1994). Perspective On Psychology. Hove: Lawrence Erlbaum Associates, Ltd.

[2] Augustin, Sally. (2009). Applied Psychology for Interior Architecture. Hoboken: John Wiley \& Sons, Inc.

[3] Hidjaz, Taufan. (2011). "Interaksi Perilaku dan Suasana Ruang di Perkantoran Kasus di 2 lokasi Kantor Pusat PT. Telkom, Bandung.” dalam Jurnal Itenas Rekarupa Vol. 1. Bandung: Institut Teknologi Nasional.

[4] Long, Kim. (2004). User Effective Buildings. Denver: Aardex Coorporation.

[5] Veitch, J., Charles, K., Farley, K.and Newsham, G. (2007)."A Model of Satisfaction with Open Plan Office Conditions:COPE Field Findings."Environmental Psycholog27(3):177-189.

[6] Fischer, G., Tarquinio, C., and Vischer, J. (2004). "Effects of the Self-Schema on Perception of Space at Work." dalam jurnal Environmental Psychology 24(2): 131-140. 
Jurnal I D E A L O G

Ide dan Dialog Indonesia

Vol.3 No.1, April 2018

ISSN Cetak 2477-0566

ISSN Elektronik 2615 - 6776 